\title{
Dexamethasone Exposure of Neonatal Rats Modulates Biliary Lipid Secretion and Hepatic Expression of Genes Controlling Bile Acid Metabolism in Adulthood Without Interfering With Primary Bile Acid Kinetics
}

\author{
YAN LIU, RICK HAVINGA, FEIKE R. VAN DER LEIJ, RENZE BOVERHOF, PIETER J. J. SAUER, FOLKERT KUIPERS, \\ AND FRANS STELLAARD
}

Center for Liver, Digestive, and Metabolic Disease, University Medical Center Groningen, 9713 GZ Groningen, The Netherlands

\begin{abstract}
Literature suggests that glucocorticoid (GC) exposure during early life may have long-term consequences into adult life. GCs are known to influence hepatic bile acid synthesis and their transport within the enterohepatic circulation. This study addresses effects of early postnatal exposure to GC on hepatic expression of key genes in bile acid metabolism and bile acid kinetics in adult rats. Male rats were treated with either dexamethasone (DEX) or saline at days 1-3 d after birth. Liver tissue and blood were collected from $2 \mathrm{~d}$ to $50 \mathrm{wk}$ of age. Bile acid kinetics were determined at week 8. DEX acutely induced hepatic mRNA levels of cholesterol $7 \alpha$-hydroxylase (Cyp7a1), cholesterol 27-hydroxylase (Cyp27), and in particular sterol $12 \alpha$-hydroxylase (Cyp8b1), whereas expression of the bile acid transporters bile salt export pump (Bsep) and sodium taurocholate cotransporting polypeptide (Ntcp) was moderately affected. Neonatal DEX administration led to increased bilary lipid secretion, decreased Cyp8B1 mRNA expression and a 3-fold higher Cyp7al/Cyp $8 b 1$ mRNA ratio in rats at week 8 compared with age-matched controls without alterations in bile acid kinetics. Therefore, neonatal DEX administration causes altered gene expressions later in life that are not translated into quantitative changes in bile acid kinetics. (Pediatr Res 63: 375-381, 2008)
\end{abstract}

$\mathrm{T}_{\mathrm{s}}$ he production of bile is an important function of the liver. Bile acids are the major organic constituents of bile exerting physiologically important functions, including generation of bile flow and facilitation of intestinal fat absorption (1). Bile acids are essential for maintenance of cholesterol homeostasis (2). Recent studies indicate that bile acids modulate expression of a variety of genes involved in bile acid, lipid, and glucose metabolism through activation of the nuclear receptor farnesoid X receptor (Fxr) (3). Disturbances in bile acid metabolism are associated with diseases such as gallstone disease (4) and familial hypertriglyceridemia $(5,6)$.

Glucocorticoids (GC) are widely used in immature newborns because of their anti-inflammatory effects (7). Increas-

Received August 10, 2007; accepted December 4, 2007.

Correspondence: Frans Stellaard, Ph.D., Center for Liver, Digestive, and Metabolic Disease, Research Laboratory Pediatrics, University Medical Centre Groningen, CMCV-2, Hanzeplein 1, 9713 GZ Groningen, The Netherlands; e-mail: F.Stellaard@med.umcg.nl

Feike R. Van Der Leij is currently at Unit Life Sciences, Van Hall University of Applied Sciences, Leeuwarden, The Netherlands.

Supported by the Graduate School Groningen University Institute for Drug exploration (GUIDE) ing evidence indicates that GC administration in early life may have long-term effects, including growth retardation (8), cardiac dilatation, and cardiac hypertrophy (9).

Studies conducted in vivo and in vitro indicate that GC, e.g., dexamethasone, affect expression of several genes involved in synthesis and enterohepatic cycling of bile acids, such as cholesterol $7 \alpha$-hydroxylase (Cyp7al), cholesterol 27 hydroxylase (Cyp27al), and sodium taurocholate cotransporting polypeptide (Ntcp) (10-12), that may lead to increased bile acid synthesis and their altered enterohepatic cycling. Enlargement of the circulating bile acid pool has been observed in neonates whose mothers were treated with dexamethasone (DEX) (13). Unfortunately, most studies are limited to acute situations. The potential long-term effects of neonatal DEX treatment on bile acid metabolism later in life are still unknown. In the present study, we evaluated bile acid metabolism in adult rats after neonatal DEX administration.

\section{MATERIALS AND METHODS}

Animals. Pregnant Wistar rats (270-300 g) were housed individually and kept under conventional housing conditions with free access to food and water. Pups were born naturally on day 21-22 of gestation. On the day of birth (day 0), male pups were randomly divided into treatment or control groups. Temperature and humidity were kept constant, and the animals had free access to food and water. An artificial $12 \mathrm{~h}$ light/12 h dark cycle was used.

Methods. Rat pups in the treatment group were injected i.p with dexamethasone 21-phosphate (DEX) at day 1,2 , and $3(0.5,0.3$, and $0.1 \mu \mathrm{g} / \mathrm{g}$ body weight, respectively) in the morning between 9:00 AM and 10:00 PM. Controls were injected with equal volumes $(10 \mu \mathrm{L} / \mathrm{g})$ of sterile pyrogen-free saline (SAL). Rats were killed at days 2, 7, 14, and 28 and at weeks 8, 24, and 50 for collection of liver tissue and blood ( $n=6$ per treatment group per age).

Additional rats of $8 \mathrm{wk}$ old were used to study cholic acid (CA) kinetics in adulthood ( $n=6$ per group). At 8 wk of age, rats of DEX and SAL groups were injected i.v. with $250 \mu \mathrm{L}$ PBS buffer containing $3 \mathrm{mg}^{2} \mathrm{H}_{4}$-CA $([2,2,4,4-$ $\left.{ }^{2} \mathrm{H}_{4}\right]$-cholic acid obtained from Isotec Inc., Miamisburg, OH) in a solution of

Abbreviations: Abcg5, ATP-binding cassette, sub-family G (WHITE), member 5; Bsep, bile salt export pump Abcb11; CA, cholic acid; CDCA, Chenodeoxycholic acid; Cyp7a1, cytochrome P450, 7a1 (cholesterol alpha-7hydroxylase); Cyp8b1, cytochrome P450, 8b1, sterol 12 alpha-hydrolase; DEX, dexamethasone; Fic-1, aminophospholipid translocase Atp8b; Fxr, farnesoid X receptor; GC, Glucocorticoids; Hmgr, HMG-CoA reductase; $\mathbf{H n f 4} \boldsymbol{\alpha}$, hepatic nuclear factor $4 \alpha, \mathrm{Nr} 2 \mathrm{a} 1$; Lxr $\boldsymbol{\alpha}$, liver $\mathrm{X}$ receptor $\alpha$; Mdr2, multidrug resistance protein 2; Mrp2, multidrug resistance-related protein 2; Ntcp, Na/taurocholate cotransporting polypeptide 1; SAL, saline; Shp, small heterodimer partner 
$0.5 \% \mathrm{NaHCO}_{3}$. Blood samples $(250 \mu \mathrm{L})$ were taken before injection and at $t=12,24,36,48,60$, and $72 \mathrm{~h}$ from the tail under anesthesia. Plasma was obtained and stored at $-20^{\circ} \mathrm{C}$ until analysis of CA isotope enrichments. After $72 \mathrm{~h}$, the rats were subjected to bile duct cannulation under pentobartital anesthesia. Bile produced during the initial $5 \mathrm{~min}$ after cannulation was discarded, and bile was sampled for $30 \mathrm{~min}$ thereafter. Feces was collected in $24 \mathrm{~h}$ portions for $3 \mathrm{~d}$ during the experiment and freeze-dried.

All experimental procedures were approved by the local Ethical Committee for Animal Experiments.

Sample preparation. Fifty micrograms of dried feces was boiled in $1 \mathrm{~mL}$ alkaline methanol $(1 \mathrm{M} \mathrm{NaOH} / \mathrm{methanol,} 1: 3 \mathrm{vol} / \mathrm{vol})$ at $80^{\circ} \mathrm{C}$ for $2 \mathrm{~h}$. After cooling down, the sample was diluted 1:9 with distilled water, and $0.1 \mathrm{~mL}$ was used for a total bile acid measurement (14). The remainder was used for bile acid isolation by reversed phase (C18) solid phase extraction (SPE). The bile acids were derivatized to the methyl ester-trimethylsilyl derivatives for gas chromatographic analysis.

Bile samples $(1 \mu \mathrm{L})$ were subjected to enzymatic deconjugation. Free bile acids were extracted with C18-SPE and derivatized to the methyl estertrimethylsilyl derivatives for gas chromatography analysis (15).

Plasma samples were prepared for isotopic analysis of bile acids by gas chromatography/mass spectrometry as described (15).

Gas chromatography. Bile acid compositions of prepared bile samples and fecal samples were determined by capillary gas chromatography using an Agilent gas chromatograph (HP 6890) equipped with a $25 \mathrm{~m} \times 0.32 \mathrm{~mm}$ CP-Sil-19 fused silica column (Varian B.V., Middelburg, The Netherlands) and a Flame Ionization Detector.

Gas chromatography/electron capture negative chemical ionization mass spectrometry. Isotope analysis of CA in plasma was performed on a ThermoFinnigan MAT SSQ7000 quadrupole gas chromatography/mass spectrometry instrument. Gas chromatographic separation was performed on a $25 \mathrm{~m} \times 0.25$ mm column $(0.25 \mu \mathrm{m}$ film thickness; AT-5MS, Alltech Associates Inc., Deerfield, IL) as described before (15).

Isotope dilution technique calculations. The isotope dilution technique and the related calculations of pool size, fractional turnover rate (FTR), and synthesis rate has been described in detail by Hulzebos et al. (15).

Fast protein liquid chromatography. Plasma concentrations of total and free cholesterol and of triglycerides were measured with commercially available kits (WAKO, Neuss, Germany). Pooled plasma samples from six rat pups per group were used for lipoprotein separation by fast protein liquid chromatography (FPLC) as described previously (16).

RNA isolation and quantitative real-time PCR. Total RNA was isolated from frozen liver tissue using TRI Reagent (Sigma Chemical Co.) method according to manufactory's instructions ( $n=6$ per treatment group). The integrity of total RNA was assessed using Lab-on-a-Chip 2100 Bioanalyzer (Agilent, USA). Total RNA was reverse transcribed as described previously (17). Real-time quantitative PCR was performed using an ABI PRISM 7700 sequence detector (Applied Biosystems, Foster City, CA). Primers were obtained from Invitrogen (Carlsbad, USA). Fluorogenic probes, labeled with 6-carboxy-fluorescein and 6-carboxy-tetramethyl-rhodamine, were made by Eurogentec (Seraing, Belgium). Primer and probe sequences for $\beta$-actin, ATP-binding cassette transporter G5 (Abcg5), bile salt export pump (Bsep, Abcb11), Cyp7a1, Cyp27, Fxr (NR1H4), HMG-CoA reductase (Hmgr), and Ntcp (Slc10a1) have been described previously (18-21). Sequence of other primers and probes were listed in Table 1 . All gene expression data were standardized to $\beta$-actin.

Statistics. Data were expressed as mean \pm SD. Statistical analysis of groups was performed by the Student's $t$ test or the Mann-Whitney $U$ test. Level of significance was set at $p<0.05$. Analyses were performed by using SPSS for Windows software (SPSS, Chicago, IL).

\section{RESULTS}

Acute and chronic effects of DEX on mRNA levels of genes involved in bile acid synthesis and transport. DEX administration resulted in significantly increased hepatic gene

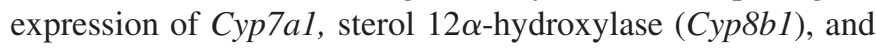
Cyp27 in 2-d-old rats compared with age-matched controls (Fig. 1). There were no differences in mRNA level in Fxr, liver $\mathrm{X}$ receptor alpha $(\operatorname{Lxr} \alpha)$, and hepatic nuclear factor 4 alpha $(H n f 4 \alpha)$ between the two groups. Both $\beta K l o t h o$ and the short heterodimer partner $(S h p)$ were increased in expression, while the fibroblast growth factor receptor 4 ( Fgf $4 r)$ mRNA level was decreased by DEX treatment at this age. There was no difference in Reverb $\alpha$ mRNA content between the two groups. The expression of the canalicular phospholipid translocator multidrug resistance protein $2(M d r 2)$ was slightly increased upon DEX treatment. The mRNA levels of genes encoding canalicular bile acid transporter Bsep (Abcb11) and the organic anion transporter multidrug resistance-related protein 2 (Mrp2), as well as the putative aminophospholipid translocase involved in Familiar Intrahepatic Cholestasis (Fic1), were significantly decreased in DEX-treated rats.

Hepatic expression of genes involved in bile acid metabolism was determined from $2 \mathrm{~d}$ to $50 \mathrm{wk}$ of age (Fig. 2). In control animals, hepatic mRNA content of genes involved in bile acid metabolism, such as Cyp7a1 and Cyp27, markedly increased from $14 \mathrm{~d}$ of age onwards and reached maximal

Table 1. Sequences of primer and probe used for real-time PCR

\begin{tabular}{|c|c|c|c|c|}
\hline & & Forward & Reverse & Probe \\
\hline Сур8b1 & & $\begin{array}{l}\text { AAGGCTGGCTTC } \\
\text { CTGAGCTT }\end{array}$ & $\begin{array}{l}\text { AACAGCTCATCG } \\
\text { GCCTCATC }\end{array}$ & $\begin{array}{l}\text { CCTGCTCCTTGT } \\
\text { CCTTGGTGCAGC }\end{array}$ \\
\hline Flc-1 & & $\begin{array}{l}\text { GTCGCCATCCGT } \\
\text { TTCCTGT }\end{array}$ & $\begin{array}{l}\text { CGCCGTTTCCAC } \\
\text { TGCTCTT }\end{array}$ & $\begin{array}{l}\text { CCTTCAATCGCTTTC } \\
\text { GATGCTTCTGGATC }\end{array}$ \\
\hline Fgf4r & & $\begin{array}{l}\text { TCGTTATCAACG } \\
\text { GCAGCAGTT }\end{array}$ & $\begin{array}{l}\text { TTGATGTCTGTT } \\
\text { GTCTTCAGGACTT }\end{array}$ & $\begin{array}{l}\text { CGGCGCTGATGGTTT } \\
\text { CCCCTACGTA }\end{array}$ \\
\hline Klotho, beta & & $\begin{array}{l}\text { GAACGGCTGGTT } \\
\text { CACAGATAGTTA }\end{array}$ & $\begin{array}{l}\text { CATCAAACTTTATTG } \\
\text { CTTGAAGAACCT }\end{array}$ & $\begin{array}{l}\text { ACCACGGCCATCTAC } \\
\text { ATGATGAAGAATTTC }\end{array}$ \\
\hline Lxr-alpha & NR1H3 & $\begin{array}{l}\text { GCTCTGCTCATA } \\
\text { GCCATCAG }\end{array}$ & $\begin{array}{l}\text { CAGGGCCTCCAC } \\
\text { ATATG GT }\end{array}$ & $\begin{array}{l}\text { TCTGCAGACCGG } \\
\text { CCCAACGTG }\end{array}$ \\
\hline Mdr2 & Abcb4 & $\begin{array}{l}\text { AGTTCACGGGCGC } \\
\text { ATCAA }\end{array}$ & $\begin{array}{l}\text { AAAAGACACTGGTG } \\
\text { GCACGTT }\end{array}$ & $\begin{array}{l}\text { CATCAAGTTCATTGGTTTC } \\
\text { CACATCCAGC }\end{array}$ \\
\hline Mrp2 & Abcc2 & $\begin{array}{l}\text { GACGACGATGATG } \\
\text { GGCTGAT }\end{array}$ & $\begin{array}{l}\text { CTTCTCATGGCCAA } \\
\text { GGAAGCT }\end{array}$ & $\begin{array}{l}\text { CCCACCATGGAGGAAAA } \\
\text { TAAATGAGG }\end{array}$ \\
\hline Shp & NR0B2 & $\begin{array}{l}\text { ACCTGCAACAGG } \\
\text { AGGCTCACT }\end{array}$ & $\begin{array}{l}\text { TGGAAGCCATGA } \\
\text { GGAGGATTC }\end{array}$ & $\begin{array}{l}\text { TCCTGGAGCCCTGGT } \\
\text { ACCCAGCTAGC }\end{array}$ \\
\hline Hnf4-alpha & NR2A1 & $\begin{array}{l}\text { ATGCCAAGGGGC } \\
\text { TGAGTGAC }\end{array}$ & $\begin{array}{l}\text { GCCGGTCGTTGA } \\
\text { TGTAATCCT }\end{array}$ & $\begin{array}{l}\text { CACCTGTGACCG } \\
\text { CAGCCGCTTG }\end{array}$ \\
\hline
\end{tabular}

Sequences already published can be found at www.labpediatricsrug.nl. 


\section{A

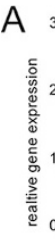

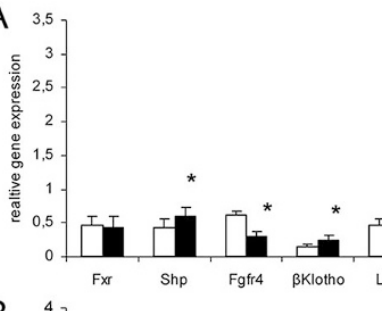

$B$

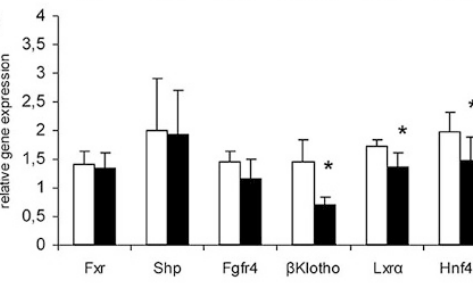

(transcriptional) control

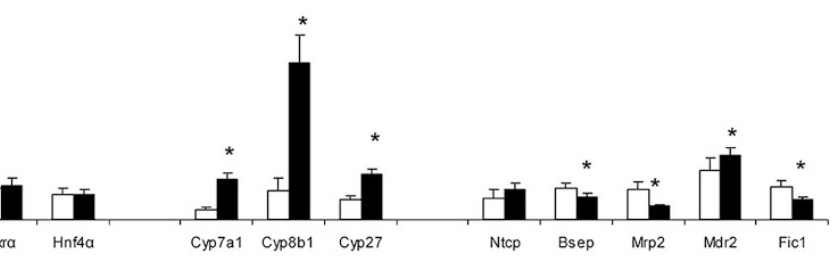

coptas

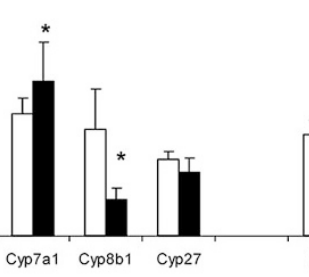

enzymes
Figure 1. Hepatic expression of genes involved in bile acid synthesis, transport and regulation at day $2(A)$ and week $8(B)$ in DEX and SAL-treated rats. Data are presented as mean $\pm \mathrm{SD}, n=6$ per group. $\square$ : SAL treated rats; $\mathbf{\square}$ : DEX treated rats. $* p<0.05$ DEX versus SAL-treated animals. levels at about 8 wk (Fig. $2 A$ and $C$ ). Cyp $8 b 1$ gene expression increased from 4 wk onward and reached to its maximal level at about 24 wk of age (Fig. 2B). The mRNA levels of genes encoding bile acid transporters and regulatory factors steadily increased during aging and reached their maximal levels at about $8 \mathrm{wk}$ of age and decreased thereafter (Fig. $2 D-I$ ). It is evident that neonatal DEX administration disturbed development of gene expression pattern into adulthood. In particular, the ratio of Cyp7al/Cyp $8 b 1$ mRNA level, which was markedly increased at $4 \mathrm{wk}$ of age in the control group, showed a delayed increase at $8 \mathrm{wk}$ of age in the DEX-treated animals. Consequently, at $8 \mathrm{wk}$ of age, the ratio of Cyp7al/Cyp $8 b 1$ mRNA was significantly increased in DEX- treated animals compared with controls (Fig. 3).
The ontogenesis of hepatic $A b c g 5$ gene expression was also affected by DEX administration. A strong induction of hepatic $A b c g 5$ was noted at $14 \mathrm{~d}$ of age in control rats, but was delayed in DEX-treated animals (Fig. 4A). There was no difference in HMG-CoA reductase $(\mathrm{Hmgr})$ gene expression pattern in DEX-treated animal compared with SAL group during lifetime (Fig. 4B), suggestive for unaltered cholesterol synthesis during the course of the experiment.

Characteristics of animals at 8 wk of age after neonatal DEX treatment. There were no significant differences in body weight and liver weight between DEX-treated rats and control rats at $8 \mathrm{wk}$ of age, but liver weight/body weight ratio was higher in DEX-treated rats (Table 2). Rats exposed to neonatal DEX administration had significantly lower plasma triglycer-
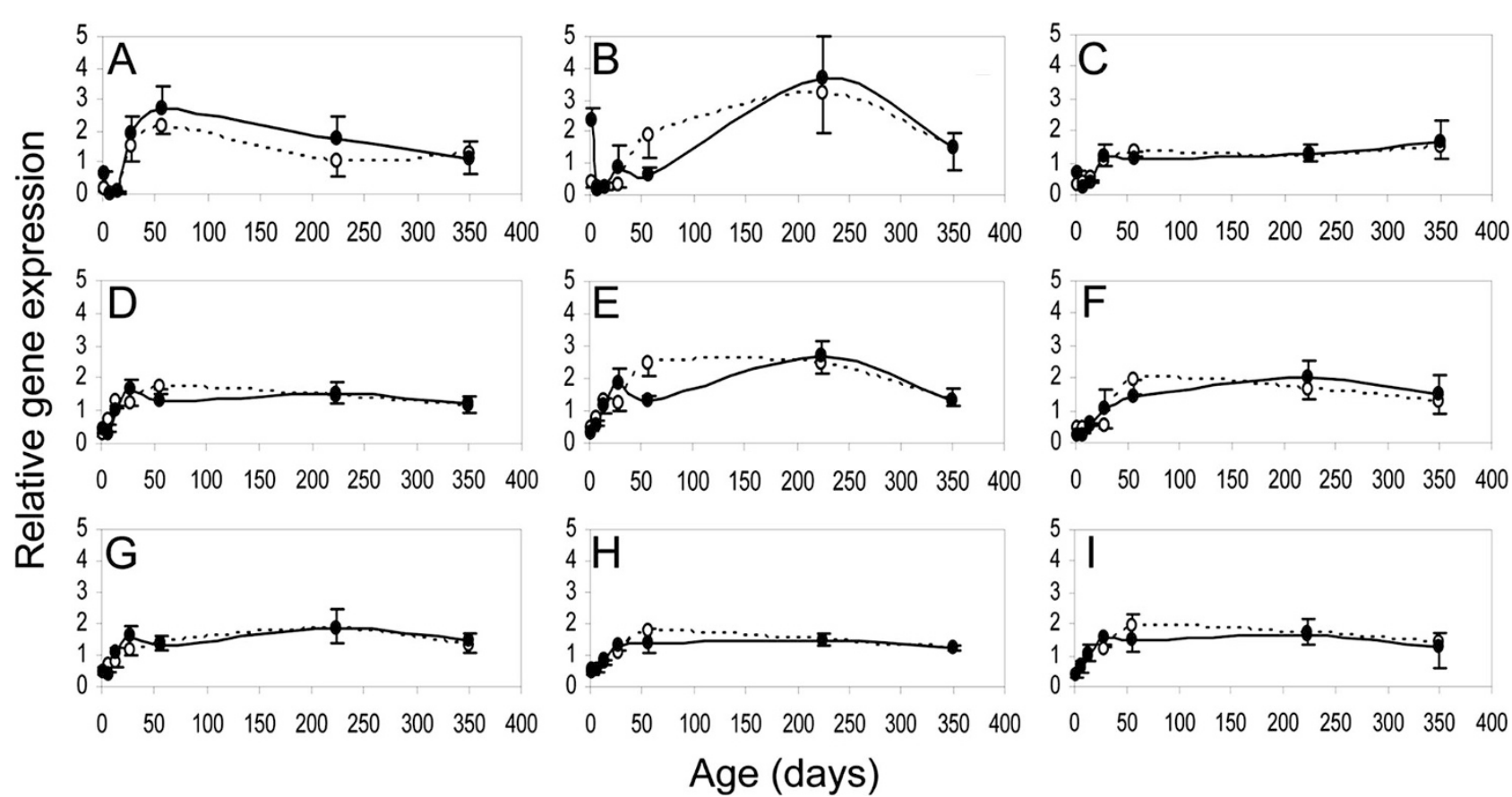

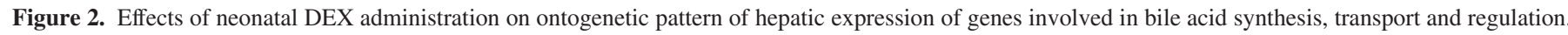

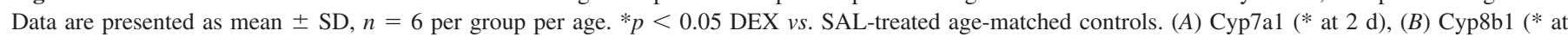

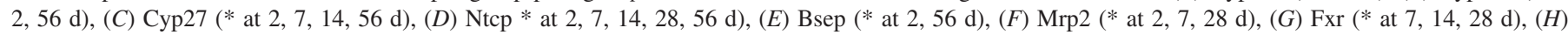
$\operatorname{Lxr} \alpha(*$ at $28,56 \mathrm{~d}),(I) \operatorname{Hnf} 4 \alpha(*$ at $28 \mathrm{~d})$. $\bigcirc$ : SAL treated rats; $\mathrm{O}$ : DEX treated rats. 


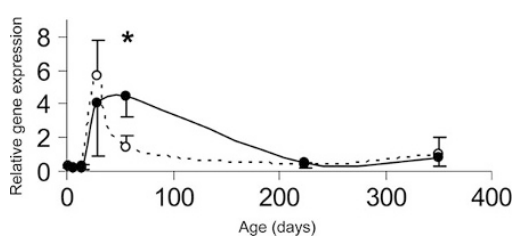

Figure 3. Ontogenetic pattern of hepatic Cyp7a1/Cyp8b1 mRNA ratio. Data are presented as mean $\pm \mathrm{SD}, n=6$ per group per age. $\bigcirc$ : SAL treated rats; ๑: DEX treated rats. ${ }^{*} p<0.05$ DEX vs. SAL-treated age-matched controls.

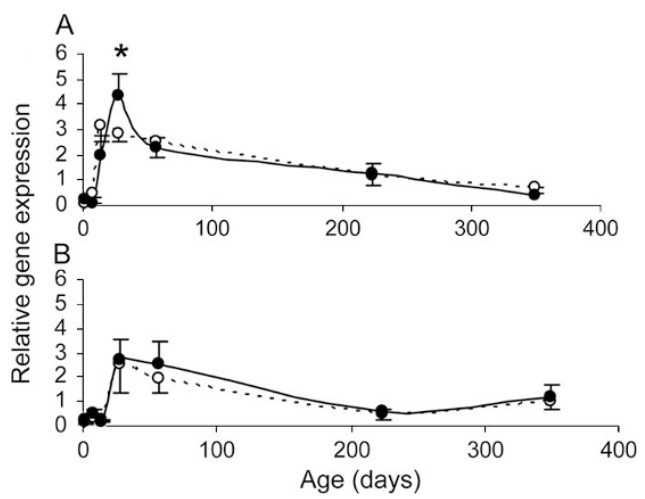

Figure 4. Ontogenetic pattern of hepatic expression of Abcg5 and Hmgr. (A) Hepatic relative gene expression of Abcg5; $(B)$ Hepatic relative gene expression of Hmgr. Data are presented as mean $\pm \mathrm{SD}, n=6$ per group per age. $(A)$ Abcg5, (B) Hmgr. $\bigcirc:$ SAL treated rats; $\bullet$ : DEX treated rats. * $p<0.05$ DEX vs. SAL-treated age-matched controls.

ide concentrations compared with controls, without differences in plasma concentrations of total cholesterol and nonesterified fatty acids between the groups. A lower triglyceride content in VLDL-sized fraction was observed in DEX-treated animals upon FPLC analysis (data not shown).

Effects of neonatal DEX administration on bile formation, bile lipid composition, and fecal bile acid excretion at $8 w k$ of age. There was no difference in bile flow between DEXand SAL-treated rats (Table 3). However, biliary cholesterol concentrations were significantly increased in DEX-treated rats. The concentrations of phospholipids and bile acids tended to be higher in DEX-treated animals, but these differences did not reach statistical difference. As a consequence, biliary output rates of bile acids, phospholipids, and cholesterol were all slightly, but significantly increased in DEXtreated rats of $8 \mathrm{wk}$ compared with the SAL group. No differences were noted between the two groups when the output rates of cholesterol and phospholipids were expressed relative to those of bile acids (Table 3).

The biliary bile acid composition showed no significant differences between two groups (Fig. 5A). The total amounts of CA-derived species (cholic and deoxycholic acids) and chenodeoxycholic acid (CDCA)-derived species (chenodeoxycholic and muricholic acids) in bile were similar in both groups (Fig. 5B). No differences were observed in the $24 \mathrm{~h}$ fecal amount, fecal total bile acid excretion (Table 3), and fecal excretion of CA-derived and CDCA-derived species (Fig. 5C).

Effects of neonatal DEX treatment on kinetic parameters of cholic acid metabolism. Analysis of plasma CA enrichment over time (Fig. 6) showed identical isotope dilution kinetics in
Table 2. Animal characteristics and plasma lipids of 8-wk-old rats with neonatal SAL or DEX treatment

\begin{tabular}{lcc}
\hline & SAL & \multicolumn{1}{c}{ DEX } \\
\hline Body weight $(\mathrm{g})$ & $287 \pm 15$ & $277 \pm 23$ \\
Liver weight $(\mathrm{g})$ & $10.9 \pm 1.0$ & $11.2 \pm 1.5$ \\
Liver weight/body weight $(\mathrm{mg} / \mathrm{g})$ & $37.9 \pm 1.8$ & $40.3 \pm 2.1^{*}$ \\
Plasma CH $(\mathrm{mM})$ & $1.96 \pm 0.29$ & $1.90 \pm 0.31$ \\
Plasma TAG $(\mathrm{mM})$ & $1.52 \pm 0.84$ & $0.79 \pm 0.29^{*}$ \\
Plasma NEFA $(\mathrm{mM})$ & $0.53 \pm 0.15$ & $0.51 \pm 0.11$ \\
\hline
\end{tabular}

Data are presented as mean $\pm \mathrm{SD}$. ( $n=6$ per group).

$* p<0.05$ DEX $v s$. SAL-treated animals.

$\mathrm{CH}$, cholesterol; TAG, triacylglycerol; NEFA, nonesterified fatty acids.

Table 3. Bile flow and biliary output rates in 8 wk rats treated with SAL or DEX. Male Wistar rats were treated with DEX or SAL at first 3 days after birth, and bile flow, and biliary output were measured at 8 wk of age

\begin{tabular}{lcc}
\hline & SAL & DEX \\
\hline $\begin{array}{l}\text { Biliary lipid concentration } \\
\quad \text { (mmol/L) }\end{array}$ & & \\
Bile acids & $38.8 \pm 5.61$ & $45.2 \pm 4.93$ \\
Cholesterol & $0.42 \pm 0.07$ & $0.55 \pm 0.09^{*}$ \\
Phospholipids & $5.39 \pm 1.01$ & $6.23 \pm 1.00$ \\
Bile flow $(\mu \mathrm{L} / 100 \mathrm{~g} \mathrm{BW} / \mathrm{min})$ & $6.64 \pm 0.96$ & $7.41 \pm 1.25$ \\
Biliary output $(\mathrm{nmol} / 100 \mathrm{~g}$ & & \\
$\quad$ BW/min) & & \\
Bile acid output & $257.5 \pm 52.9$ & $336.8 \pm 79.6^{*}$ \\
Phospholipid output & $35.2 \pm 5.02$ & $45.9 \pm 8.90^{*}$ \\
Cholesterol output & $2.76 \pm 0.56$ & $4.16 \pm 1.34^{*}$ \\
CH/PL output ratio & $0.08 \pm 0.01$ & $0.09 \pm 0.02$ \\
CH/BA output ratio & $0.011 \pm 0.003$ & $0.012 \pm 0.001$ \\
PL/BA output ratio & $0.14 \pm 0.03$ & $0.14 \pm 0.02$ \\
Fecal mass $(\mathrm{g} / \mathrm{d})$ & $2.89 \pm 0.56$ & $3.06 \pm 0.57$ \\
Fecal BA excretion $(\mu \mathrm{mol} / \mathrm{d})$ & $122 \pm 56$ & $124 \pm 64$ \\
BA synthesis $(\mu \mathrm{mol} / \mathrm{d})$ & $121 \pm 24$ & $101 \pm 28$ \\
\hline
\end{tabular}

BA synthesis was calculated by multiplying the cholic acid synthesis by the ratio of total fecal BA excretion/fecal excretion of cholic acid derived bile acids.

Data are presented as mean $\pm \mathrm{SD}$. $(n=6$ per group $)$.

$* p<0.05$ DEX vs. SAL-treated animals.

BW, body weight; $\mathrm{CH}$, cholesterol; PL, phospholipids; BA, bile acids.

SAL- and DEX- treated animals (Fig. 6A). The fractional turnover rate of CA was similar in SAL- and DEX- treated rats (0.54 \pm 0.13 vs. $0.48 \pm 0.15$ pools/d) (Fig. $6 B$ ). CA pool size was also identical in SAL- and DEX- treated rats $(50.1 \pm 10.9 \mathrm{vs}$. $53.4 \pm 10.6 \mu \mathrm{mol}$ ) (Fig. $6 C$ ). There was no difference between DEX- and SAL-treated animals with respect to the CA synthesis rate $(26.1 \pm 3.0 v s .25 .0 \pm 6.5 \mu \mathrm{mol} / \mathrm{d})($ Fig. $6 D)$.

\section{DISCUSSION}

In the present study, we evaluated the effect of neonatal DEX administration on developmental patterns in gene expressions involved in bile acid metabolism in young adult rats. Our data show that DEX administration acutely increases expression of genes involved in bile acid metabolism in 2-d-old rats, associated with altered ontogenetic gene expression pattern into adult ages. Most strikingly, at day 2 expressions of Cyp7a1, Cyp $8 b 1$, and Cyp27 were increased 2-4 fold under DEX treatment, whereas after 8 wk only the expression of Cyp7al was still increased. In contrast, the expression of 


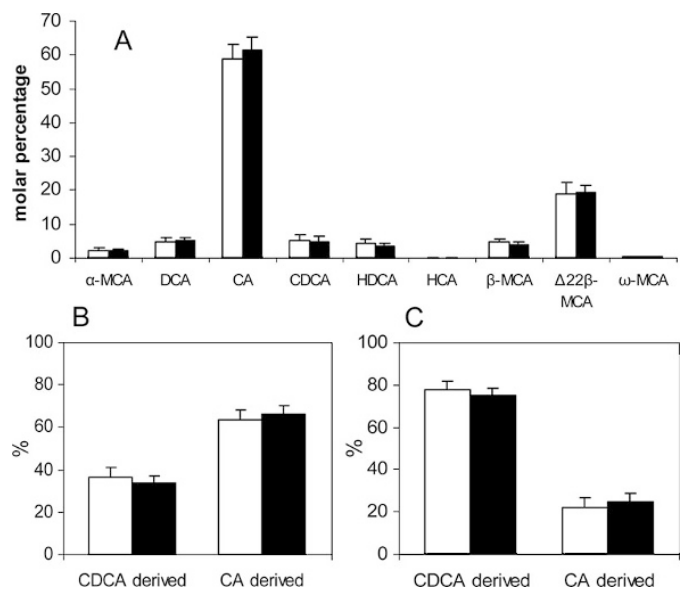

Figure 5. Effect of neonatal DEX administration on bile acid composition in bile and feces in rats of $8 \mathrm{wk}$ of age. Data are presented as mean $\pm \mathrm{SD}, n=$ 6 per group. (A) Biliary bile acid composition, $(B)$ contributions in bile of cholic acid derived bile acids and chenodeoxycholic acid derived bile acids, (C) contributions in feces of cholic acid derived bile acids and chenodeoxycholic acid derived bile acids. CA, cholic acid; CDCA, chenodeoxycholic acid. $\square$ : SAL treated rats; $\mathbf{\square}$ : DEX treated rats.

Cyp8b1 after DEX treatment was 2.5-fold lower than in the control group. However, despite strong alterations in hepatic gene expression that existed at $8 \mathrm{wk}$ of age in DEX-treated animals, CA kinetic parameters, i.e., synthesis, fractional turnover rate, and pool size were not different.

Cyp7a1 catalyzes the rate-controlling step in the conversion of cholesterol to bile acids via the so-called "neutral" pathway while Cyp27 initiates bile acid synthesis via the "acidic" pathway. Cyp $8 b 1$ controls the ratio in which $12 \alpha$-hydroxylated bile acid species are being formed. This step is also highly regulated. Bile acids act via a feedback mechanism to repress Cyp7al transcription and this is partly achieved through activation of the nuclear bile acid receptor farnesoid
$\mathrm{X}$ receptor (Fxr). This leads to induction of the orphan nuclear receptor small heterodimer partner $(S h p)$, which then displaces liver Receptor Homolog-1 (Lrh-1), from the Cyp7al gene promoter to repress gene transcription. Mice lacking Fxr or Shp have increased Cyp7al gene expression and a corresponding increase in bile acid synthesis (22). Mice lacking fibroblast growth factor receptor 4 ( $F g f r 4)$, a receptor for intestine-derived fibroblast growth factor 15 (Fgf15), have increased Cyp $7 a 1$ mRNA levels and a corresponding increase in bile acid synthesis (23). $\beta$ Klotho is a membrane protein with extensive similarity to Klotho, a protein that seems to function as an anti-aging hormone in mammals. $\beta$ Klotho is predominantly expressed in liver and pancreas and findings from Ito et al. have shown that $\beta$ Klotho may suppress bile acid synthesis in vivo (24). $\beta$ Klotho-null mice exhibit alterations of bile acid homeostasis showing elevated $C y p 7 a 1$ and Cyp8b1 mRNA levels (25). In addition, rodent Cyp7al gene expression may be activated by $L x r \alpha$ and $H n f 4 \alpha$ (26).

GC acutely enhances hepatic gene expression of Cyp7al $(27,28)$ and Cyp27 (12) in cultured hepatocytes. Surprisingly, neither Cyp7al gene expression nor activity was decreased upon adrenalectomy in rats (29). In the present experiment, we found that Cyp7al and Cyp27 expression was strongly induced upon DEX treatment in neonatal rats. Cyp $8 b 1$ gene expression was stimulated even stronger by DEX treatment, which has not been reported before. These effects are unlikely due to interference with Shp or $\beta$ Klotho signaling, because expression of these genes was actually increased rather than decreased upon DEX treatment. Reduction of $\mathrm{Fgftr}$ expression may contribute to a derepressed Cyp $7 a 1$ expression; yet, direct effects on Cyp7al promoter by DEX-activated glucocorticoid receptor are more likely involved.

A number of transporter proteins facilitate hepatocytic bile acid uptake (Ntcp, Slc10a1) and bile acid export (Bsep,
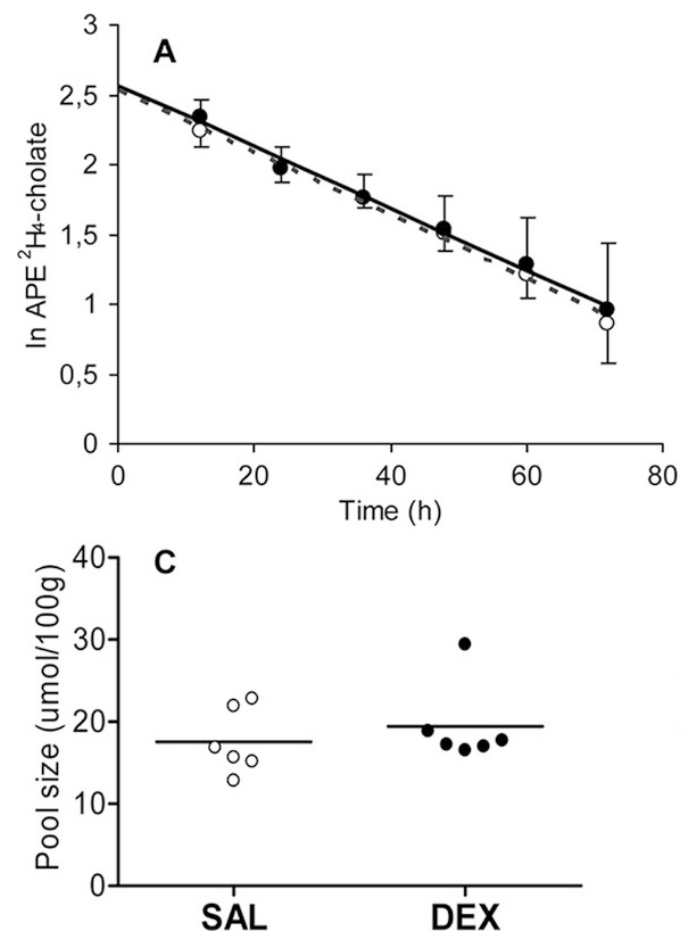

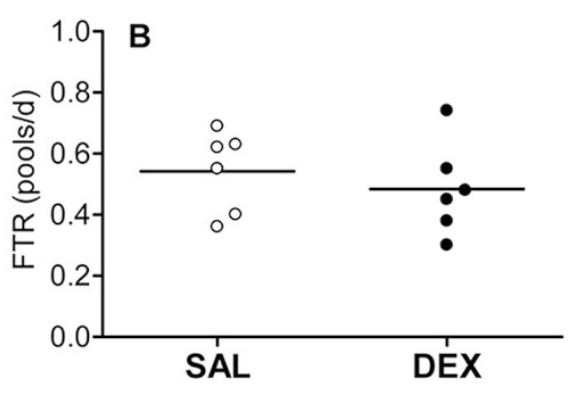

Figure 6. Effects of neonatal DEX administration on cholic acid kinetics at $8 \mathrm{wk}$ of age. (A) Decay of i.v. administered $\left[{ }^{2} \mathrm{H}_{4}\right]$ cholate in SAL $(O)$ and DEX treated rats (•), (B) fractional turnover rate (FTR), $(C)$ pool size, and $(D)$ synthesis rate. Data are presented as mean $\pm \mathrm{SD} n=6$ per group.

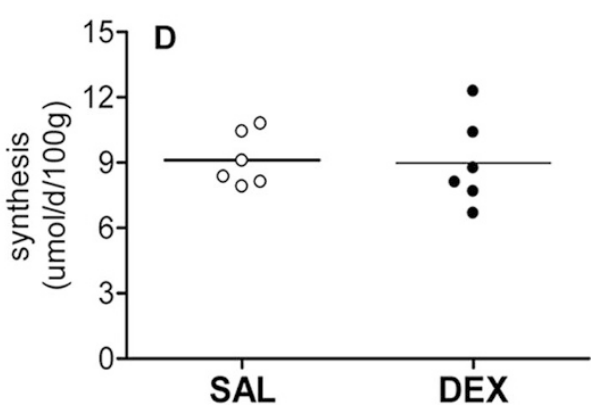


Abcb11), phospholipid transport into bile (Mdr2, Abcb4), and biliary secretion of dianionic conjugates, e.g., sulfate and glucuronide export (Mrp2, Abcc2). Fic-1(Atp8b1) is located at the canalicular membrane, presumably functions as a aminophospholipid floppase and plays a role in canalicular bile formation (30). In contrast to previous studies showing that GC increased expression of Mrp2 and decreased that of Ntcp in vitro (31), we found that DEX stimulates Ntcp and Mdr2 gene expression in vivo and decreases gene expression of Bsep, Mrp2, and Fic-1. Intriguingly, Fxr, Lxr $\alpha$, and Hnf4 $\alpha$, i.e., nuclear receptors involved in regulation of bile acid transport, were not altered by DEX. It was found that GC may stimulate hepatic expression of $H n f 4 \alpha$ in prenatal and adult situation $(25,32)$. We assume that $H n f 4 \alpha$ might not be sensitive to DEX stimulation in liver of 2-d-old rats, contributing to the different findings observed in prenatal and adult situations.

In this study, Cyp7al gene expression in untreated rats increased sharply after $14 \mathrm{~d}$ to reach a peak at $8 \mathrm{wk}$ of age and declined thereafter. DEX treatment had only marginal effects on Cyp7al expression on the long run. The developmental pattern of Cyp $8 b 1$ expression strongly differed from that of Cyp7al, with a peak observed at week 24. In this case, neonatal DEX expression did affect the developmental pattern, i.e., delayed the onset of induction. Consequently, the ratio Cyp7al/Cyp8b1 mRNA was three times higher at week 8 in DEX-treated rats, indicative for a relative change in CA versus CDCA synthesis. In contrast to Cyp7a1 and Cyp8b1, expression of Cyp 27 only slightly increased after weaning and remained stable during adulthood. Hepatic expression of Ntcp/ Slc10a1, Bsep/Abcb11, and Mrp2/Abcc2 showed a gradual increase into adulthood, which was slightly affected by DEX treatment, mainly during the first 8 wk of age. Likewise, expression of nuclear receptors $F x r, L x r \alpha$, and $H n f 4 \alpha$ showed gradual increases into adulthood with relatively minor effects of DEX exposure in the neonatal period. In contrast, DEX appeared to delay maturation of $A b c g 5$ expression. Abcg5 is critically involved in hepatobililary cholesterol secretion acting as a heterodimer with ATP-binding cassette transporter G8 (Abcg8). In untreated rats, Abcg5 expression increased to maximal levels at day 14 , while maximal levels were reached only at 4 wk upon DEX-treatment. Both in treated and untreated rats, $A b c g 5$ expression returned to very low levels at week 50. Also Hmgr, encoding the rate-controlling enzyme in cholesterol biosynthesis, showed a clear age-dependent expression pattern, with highest expression at young adult age (week 4 and 8), but remained unaffected by DEX treatment.

Based on gene expression data, specific changes in bile acid metabolism and bile formation were expected to occur $8 \mathrm{wk}$ after neonatal DEX treatment. Particularly, we expected a decrease in the relative contribution of CA and its derivatives and changes in kinetic parameters of this bile acid species. Indeed, upon bile duct canulation, we found a slight increase in total biliary bile acid secretion in DEX-treated animals, associated with significant increases in biliary cholesterol and phospholipids output rates. The latter were likely due to the higher bile acid secretion because cholesterol/bile acid and phospholipids/bile acid ratios remained unaffected upon DEX treatment, in accordance with similar expression levels of
Abcg 5 and Mdr2 in both groups. Surprisingly, no differences in CA pool sizes, fractional turnover rates, and synthesis rates were found between the groups, confirmed by identical fractions of CDCA and CA derived bile acid species in bile and feces of these animals. This outcome underscores that quantification of mRNA levels of genes that control putative "rate-controlling steps" in biochemical pathways does not by definition indicate the magnitude of the actual metabolic flux through this pathway. A large number of differences found in mRNA expression levels after $8 \mathrm{wk}$ were found to be statistically significant. However, most differences were relatively small. This may explain why the differences in expression are not translated into differences in fluxes. In this study, only the expression of genes involved in hepatic bile acid metabolism was measured. The kinetics of the enterohepatic circulation of bile acids is also determined by the intestinal transport proteins like the sodium dependent bile acid transporter (Asbt, Slc10a2), intestinal bile acid binding protein (i-Babp), and organic solute transporters $(\mathrm{Ost} \alpha / \beta)$ regulating bile acid absorption in the ileum. Effects of DEX treatment on intestinal bile acid metabolism have not been investigated. However, the identical cholic acid kinetics and identical ratios of CA derived and CDCA derived metabolites in bile and feces suggest that intestinal handling of bile acids is not affected by DEX treatment.

Thus, DEX administration to neonatal rats exerts strong and acute effects on expression of genes involved in bile acid metabolism, with more subtle consequences lasting into adulthood. Consequences of early DEX treatment on gene expression and biliary lipid secretion later in life do only translate to a very limited extent into quantitative changes in primary bile acid metabolism in rats.

Acknowledgments. We thank Fjodor van der Sluijs for the primer design and Theo Boer for the mass spectrometry analyses.

\section{REFERENCES}

1. Hofmann AF 1999 Bile acids: the good, the bad, and the ugly. News Physiol Sci 14:24-29

2. Redinger RN 2003 Nuclear receptors in cholesterol catabolism: molecular biology of the enterohepatic circulation of bile salts and its role in cholesterol homeostasis. J Lab Clin Med 142:7-20

3. Claudel T, Staels B, Kuipers F 2005 The Farnesoid X receptor: a molecular link between bile acid and lipid and glucose metabolism. Arterioscler Thromb Vasc Biol 25:2020-2030

4. Castro J, Amigo L, Miquel JF, Gälman C, Crovari F, Raddatz A, Zanlungo S, Jalil R, Rudling M, Nervi F 2007 Increased activity of hepatic microsomal triglyceride transfer protein and bile acid synthesis in gallstone disease. Hepatology 45:12611266

5. Duane WC 1995 Abnormal bile acid absorption in familial hypertriglyceridemia. J Lipid Res 36:96-107

6. Angelin B, Hershon KS, Brunzell JD 1987 Bile acid metabolism in hereditary forms of hypertriglyceridemia: evidence for an increased synthesis rate in monogenic familial hypertriglyceridemia. Proc Natl Acad Sci USA 84:5434-5438

7. Yeh TF, Lin YJ, Hsieh WS, Lin HC, Lin CH, Chen JY, Kao HA, Chien CH 1997 Early postnatal dexamethasone therapy for the prevention of chronic lung disease in preterm infants with respiratory distress syndrome: a multicenter clinical trial. Pediatrics 100:E3

8. Halliday HL 2001 The effect of postnatal steroids on growth and development J Perinat Med 29:281-285

9. Bal MP, de Vries WB, van der Leij FR, van Oosterhout MF, Baan J, van der Wall EE, van Bel F, Steendijk P 2005 Left ventricular pressure-volume relationships during normal growth and development in the adult rat-studies in 8- and 50-weekold male Wistar rats. Acta Physiol Scand 185:181-191

10. Simon FR, Fortune J, Iwahashi M, Qadri I, Sutherland E 2004 Multihormonal regulation of hepatic sinusoidal Ntcp gene expression. Am J Physiol Gastrointest Liver Physiol 287:G782-G794 
11. Stravitz RT, Hylemon PB, Heuman DM, Hagey LR, Schteingart CD, Ton-Nu HT, Hofmann AF, Vlahcevic ZR 1993 Transcriptional regulation of cholesterol 7 alphahydroxylase mRNA by conjugated bile acids in primary cultures of rat hepatocytes. J Biol Chem 268:13987-13993

12. Stravitz RT, Vlahcevic ZR, Russell TL, Heizer ML, Avadhani NG, Hylemon PB 1996 Regulation of sterol 27-hydroxylase and an alternative pathway of bile acid biosynthesis in primary cultures of rat hepatocytes. J Steroid Biochem Mol Biol 57:337-347

13. Watkins JB, Szczepanik P, Gould JB, Klein P, Lester R 1975 Bile salt metabolism in the human premature infant. Preliminary observations of pool size and synthesis rate following prenatal administration of dexamethasone and phenobarbital. Gastroenterology 69:706-713

14. Mashige F, Imai K, Osuga T 1976 A simple and sensitive assay of total serum bile acids. Clin Chim Acta 70:79-86

15. Hulzebos CV, Renfurm L, Bandsma RH, Verkade HJ, Boer T, Boverhof R, Tanaka H, Mierau I, Sauer PJ, Kuipers F, Stellaard F 2001 Measurement of parameters of cholic acid kinetics in plasma using a microscale stable isotope dilution technique: application to rodents and humans. J Lipid Res 42:1923-1929

16. Voshol PJ, Havinga R, Wolters H, Ottenhoff R, Princen HM, Oude Elferink RP, Groen AK, Kuipers F 1998 Reduced plasma cholesterol and increased fecal sterol loss in multidrug resistance gene 2 P-glycoprotein-deficient mice. Gastroenterology 114:1024-1034

17. Bloks VW, Plosch T, van Goor H, Roelofsen H, Baller J, Havinga R, Verkade HJ, van Tol A, Jansen PL, Kuipers F 2001 Hyperlipidemia and atherosclerosis associated with liver disease in ferrochelatase-deficient mice. J Lipid Res 42:41-50

18. Grefhorst A, Elzinga BM, Voshol PJ, Plosch T, Kok T, Bloks VW, van der Sluijs FH, Havekes LM, Romijn JA, Verkade HJ, Kuipers F 2002 Stimulation of lipogenesis by pharmacological activation of the liver $\mathrm{X}$ receptor leads to production of large, triglyceride-rich very low density lipoprotein particles. J Biol Chem 277:34182-34190

19. Hulzebos CV, Wolters H, Plosch T, Kramer W, Stengelin S, Stellaard F, Sauer PJ, Verkade HJ, Kuipers F 2003 Cyclosporin a and enterohepatic circulation of bile salts in rats: decreased cholate synthesis but increased intestinal reabsorption. J Pharmacol Exp Ther 304:356-363

20. Plosch T, Kok T, Bloks VW, Smit MJ, Havinga R, Chimini G, Groen AK, Kuipers F 2002 Increased hepatobiliary and fecal cholesterol excretion upon activation of the liver X receptor is independent of ABCA1. J Biol Chem 277:33870-33877
21. Kok T, Hulzebos CV, Wolters H, Havinga R, Agellon LB, Stellaard F, Shan B, Schwarz M, Kuipers F 2003 Enterohepatic circulation of bile salts in farnesoid X receptor-deficient mice: efficient intestinal bile salt absorption in the absence of ileal bile acid-binding protein. J Biol Chem 278:41930-41937

22. Chiang JY 2004 Regulation of bile acid synthesis: pathways, nuclear receptors, and mechanisms. J Hepatol 40:539-551

23. Yu C, Wang F, Kan M, Jin C, Jones RB, Weinstein M, Deng CX, McKeehan WL 2000 Elevated cholesterol metabolism and bile acid synthesis in mice lacking membrane tyrosine kinase receptor FGFR4. J Biol Chem 275:15482-15489

24. Ito S, Fujimori T, Furuya A, Satoh J, Nabeshima Y, Nabeshima Y 2005 Impaired negative feedback suppression of bile acid synthesis in mice lacking betaKlotho. J Clin Invest 115:2202-2208

25. Nyirenda MJ, Dean S, Lyons V, Chapman KE, Seckl JR 2006 Prenatal programming of hepatocyte nuclear factor 4alpha in the rat: a key mechanism in the 'foetal origins of hyperglycaemia'? Diabetologia 49:1412-1420

26. Crestani M, De FE, Caruso D, Mitro N, Gilardi F, Vigil Chacon AB, Patelli R, Godio C, Galli G 2004 LXR (liver X receptor) and HNF-4 (hepatocyte nuclear factor-4): key regulators in reverse cholesterol transport. Biochem Soc Trans 32:92-96

27. Princen HM, Meijer P, Hofstee B 1989 Dexamethasone regulates bile acid synthesis in monolayer cultures of rat hepatocytes by induction of cholesterol 7 alphahydroxylase. Biochem J 262:341-348

28. Ellis E, Goodwin B, Abrahamsson A, Liddle C, Mode A, Rudling M, Bjorkhem I, Einarsson C 1998 Bile acid synthesis in primary cultures of rat and human hepatocytes. Hepatology 27:615-620

29. Pandak WM, Heuman DM, Redford K, Stravitz RT, Chiang JY, Hylemon PB, Vlahcevic ZR 1997 Hormonal regulation of cholesterol 7alpha-hydroxylase specific activity, mRNA levels, and transcriptional activity in vivo in the rat. J Lipid Res 38:2483-2491

30. Trauner M, Boyer JL 2003 Bile salt transporters: molecular characterization, function, and regulation. Physiol Rev 83:633-671

31. Turncliff RZ, Meier PJ, Brouwer KL 2004 Effect of dexamethasone treatment on the expression and function of transport proteins in sandwich-cultured rat hepatocytes. Drug Metab Dispos 32:834-839

32. Oyadomari S, Matsuno F, Chowdhury S, Kimura T, Iwase K, Araki E, Shichiri M, Mori M, Takiguchi M 2000 The gene for hepatocyte nuclear factor (HNF)-4alpha is activated by glucocorticoids and glucagon, and repressed by insulin in rat liver. FEBS Lett 478:141-146 